\title{
A Modified ESC Algorithm for MPPT Applied to a Photovoltaic System under Varying Environmental Conditions
}

\author{
Arnaud Flanclair Tchouani Njomo $\mathbb{D}^{1,2}$ Godpromesse Kenne $\mathbb{D}^{2}{ }^{2}$ \\ Rostand Marc Douanla $(1),{ }^{1,2}$ and Lionel Leroy Sonfack $(\mathbb{1})^{1,2}$ \\ ${ }^{1}$ Unité de Recherche de Matière Condensée, d'Electronique et de Traitement de Signal (UR-MACETS), Département de Physique, \\ Faculté des Sciences, Université de Dschang, B.P. 69 Dschang, Cameroon \\ ${ }^{2}$ Unité de Recherche d'Automatique et d'Informatique Appliquée (UR-AIA), Département de Génie Electrique IUT FOTSO \\ Victor Bandjoun, Université de Dschang, B.P. 134 Bandjoun, Cameroon
}

Correspondence should be addressed to Arnaud Flanclair Tchouani Njomo; tchouani1@gmail.com

Received 27 February 2020; Revised 22 June 2020; Accepted 28 July 2020; Published 13 August 2020

Academic Editor: Francesco Riganti-Fulginei

Copyright (C) 2020 Arnaud Flanclair Tchouani Njomo et al. This is an open access article distributed under the Creative Commons Attribution License, which permits unrestricted use, distribution, and reproduction in any medium, provided the original work is properly cited.

\begin{abstract}
Photovoltaic solar energy is one of the most important renewable energy sources. However, the production of this energy is nonlinear and varies depending on atmospheric parameters. Therefore, the operating point of the photovoltaic panel (PV) does not always coincide with the maximum power point (MPP). A mechanism that allows the research of the maximum power point known as maximum power point tracking (MPPT) algorithm is then needed to yield the maximum power permanently. This paper presents an intelligent control technique based on the ESC (Extremum Seeking Control) method for MPPT under varying environmental conditions. The proposed technique is an improvement of the classical ESC algorithm with an additional loop in order to increase the convergence speed. A detailed stability analysis is given not only to ensure a faster convergence of the system towards an adjustable neighborhood of the optimum point but also to confirm a better robustness of the proposed method. In addition, simulation results using Matlab/Simulink environment and experimental results using Arduino board are presented to demonstrate that the proposed modified ESC method performs better than the classical ESC under varying atmospheric conditions.
\end{abstract}

\section{Introduction}

Inexhaustible, without pollution and present all over the globe, solar energy is one of the most important sources of renewable energy. It has attracted a lot of attention in recent decades [1-3]. The low environmental impact and wide availability of solar irradiation on the earth make photovoltaic (PV) systems one of the most viable alternatives to electricity generation [4-6]. However, changes in atmospheric parameters (cloud cover, abrupt temperature changes) cause the change in energy radiation and thus have a significant impact on the efficiency of photovoltaic systems. Therefore, a mechanism that allows the research and tracking of the maximum power point is used so that the maximum power of the photovoltaic panel is permanently generated in any environmental or ambient condition [7]. Different types of MPPT methods have been developed and implemented depending on aspects such as complexity, sensors required, convergence speed, and cost [8-15]. Among the research works on maximum power point extraction techniques proposed in the literature, incremental conductance (IC) [16] and perturb and observe ( $\mathrm{P} \& \mathrm{O})$ [17] algorithms have attracted a lot of interest because of their performance and simplicity of development $[18,19]$. One of the main drawbacks of these two algorithms is the relatively low convergence speed [19]. During abrupt changes in atmospheric conditions, these two algorithms may have difficulties tracking the point of maximum power with precision. These facts result in dramatic decrease in the performance of the PV system [20]. For this reason, recently, other adaptive algorithms 


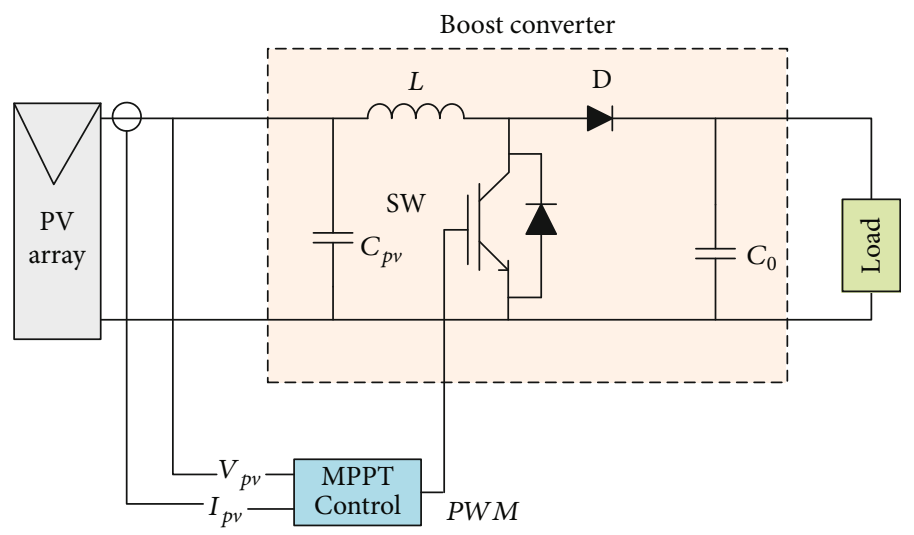

Figure 1: Photovoltaic system.

such as extremum seeking control (ESC) have been proposed [21]. Although faster than $\mathrm{P} \& \mathrm{O}$ and IC algorithms [22], the convergence speed is still a challenge for this algorithm.

In this work, an intelligent control technique based on the ESC algorithm for maximum power point tracking (MPPT) during unexpected changes in atmospheric conditions is proposed. This algorithm aims at increasing the convergence speed in order to improve system performance. A detailed stability analysis of this extremum search control technique is provided to ensure the convergence of the system to an adjustable neighborhood of the optimum operating point.

To evaluate the performance of the algorithm, the proposed modified ESC-based MPPT method is implemented on a DC-DC boost converter, and its performance is compared to that of the traditional ESC algorithm using Matlab/Simulink environment. In addition, the experimental validation using an Arduino Mega board is carried out.

The rest of the paper is organized as follows: Section 2 presents in detail the elements of a PV conversion system. In Section 3, the classical extremum seeking algorithm and the proposed modified ESC are introduced, and the stability of its averaged model is investigated. Simulation and experimental results are presented in Sections 4 and 5. Concluding remarks are presented in Section 6.

\section{A Block Diagram of a PV Control System}

Figure 1 illustrates the structure of the photovoltaic system adopted in this work. This structure consists of a solar panel, DC-DC converter, and the MPPT controller. Details of each component are described below.

2.1. Electrical Diagram of a Photovoltaic Cell. In order to permanently extract the maximum power from a photovoltaic system, we consider the equivalent electrical model of a photovoltaic cell shown in Figure 2 [23-25]. In the literature, various research works on the control of photovoltaic systems have shown that this model is a sufficiently accurate representation of the physical system for the design of MPPT controllers $[24,26,27]$. This model consists of an ideal current source $\left(I_{p h}\right)$ in parallel with a diode and a resistor $\left(R_{p}\right)$, all together in series with the resistor $\left(R_{s}\right)$, which models con-

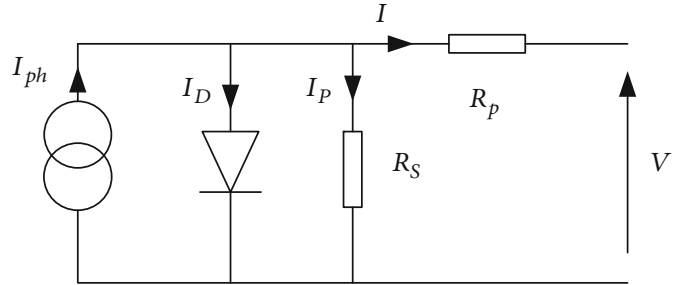

Figure 2: Equivalent circuit of a photovoltaic cell.

tactor and semiconductor material resistance. The ideal current source delivers current in proportion to solar flux $(\mathrm{G})$ and is also a function of the temperature (T). The diode models the effects of the semiconductor material and also depends on the temperature.

Applying the Kirchhoff's first law, the current supplied I by the cell is:

$$
I=I_{p h}-I_{D}-I_{P}
$$

Where $I_{D}$ is the current in the diode, $I_{p h}$ is the photocurrent (current generated by radiation), and $I_{P}$ is the current derived by the parallel resistor. $I_{p}$ And $I_{D}$ are written as in (2) and (3), respectively.

$$
\begin{gathered}
I_{p}=\frac{V+I \cdot R_{S}}{R_{P}}, \\
I_{D}=I_{S}\left[\exp \left(\frac{V+I \cdot R_{S}}{n V_{T}}\right)-1\right] .
\end{gathered}
$$

In the above expressions cell, $V$ and $V_{T}$ are the cell output and the thermic voltages, respectively. $I_{S}$ is the diode saturation current and depends on the temperature, $R_{S}$ is the series resistor modeling the resistances of the material or contacts, and $n$ is the nonideality factor of the junction between 1 and 5 in practice. $V_{T}$ is expressed as follows:

$$
V_{T}=\frac{K T}{q} .
$$




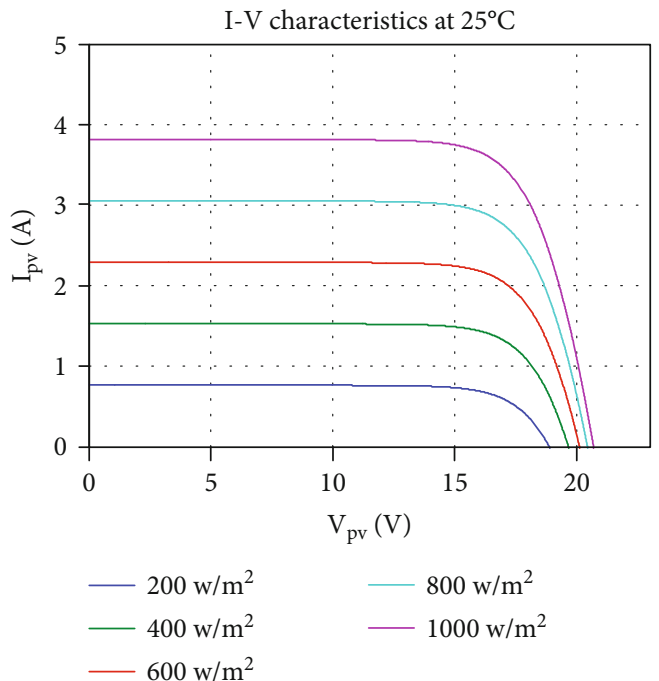

(a)

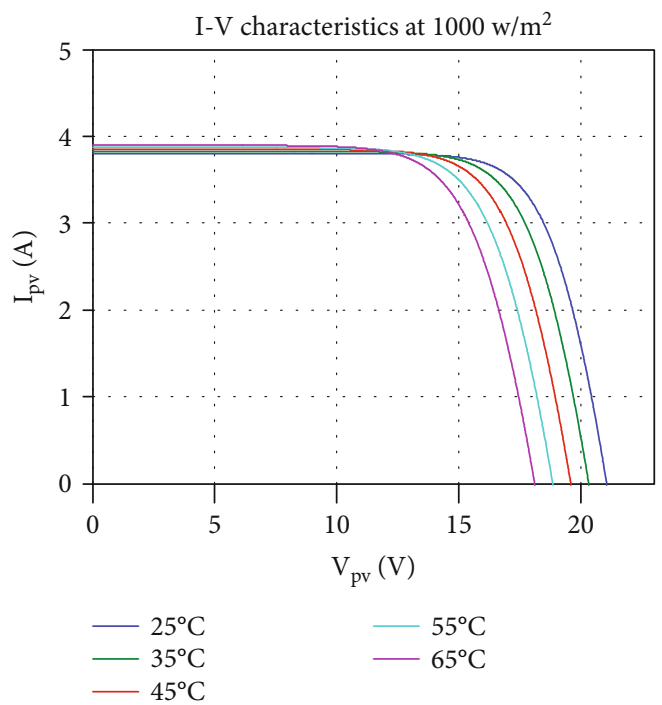

(c)

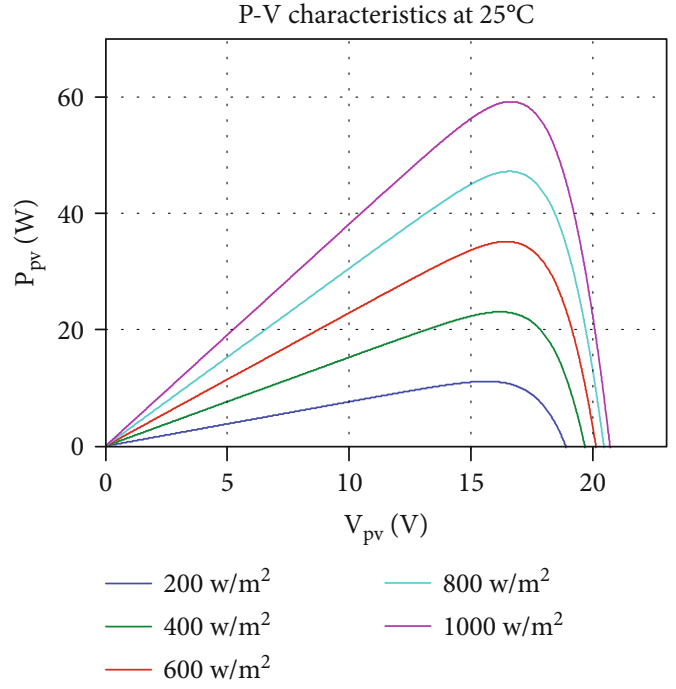

(b)

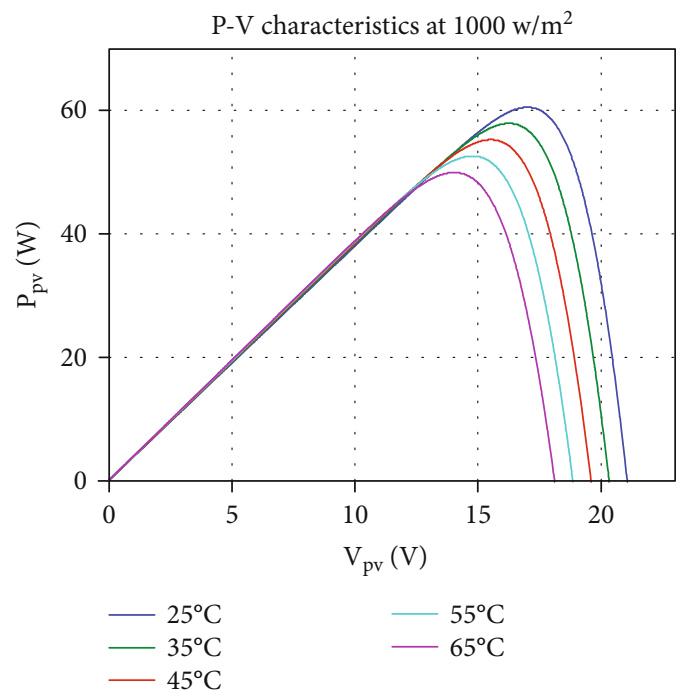

(d)

FIGURE 3: Current-voltage (a) and power-voltage characteristics (b) (case of constant temperature and variable irradiation) and currentvoltage (c) and power-voltage characteristics (d) (case of constant irradiation and variable temperature).

With $T$ is the effective cell temperature in kelvin, $K$ is the Boltzmann constant $\left(1,381 \cdot 10^{-23} J / K\right)$ and $q$ is the electron charge $\left(1,602 \cdot 10^{9} \mathrm{C}\right)$.

Saturation current is expressed as follows:

$$
I_{S}=I_{S C} /\left[\exp \left(\frac{V_{O C}}{n V_{T}}\right)-1\right]
$$

Where $I_{S C}$ is the reference short-circuit current and $V_{O C}$ is the open-circuit voltage.

$$
I_{S C}=I_{S C R}\left(\frac{G}{1000}\right),
$$

Where $I_{S C R}$ is the reference short-circuit current, $G$ is the solar irradiation in $\mathrm{W} / \mathrm{m}^{2}$.
Thus, in static, the behavior of a PV cell consisting of a silicon-based PN junction can be described by the following equation:

$$
I=I_{p h}-I_{S}\left[\exp \left(\frac{V+I \cdot R_{S}}{n V_{T}}\right)-1\right]-\frac{V+I \cdot R_{S}}{R_{p}} .
$$

Figure 3 presents the characteristics of the photovoltaic panel with parameters given in Table 1 . It is observed in Figures 3(a) and 3(b) that at constant temperature the MPP varies with irradiance. In Figures 3(c) and 3(d), it is seen that at constant irradiance the MPP changes with the temperature. From the above observations, one can conclude that both the temperature and the irradiance variations modify the MPP of the PV. It is therefore 
TABLE 1: Electrical characteristics of the MSX-60 photovoltaic.

\begin{tabular}{lc}
\hline PV panel parameters & Value \\
\hline Maximum power, (Pmax) & $60 \mathrm{w}$ \\
Maximum power point voltage (Vmpp) & $17.1 \mathrm{~V}$ \\
Maximum power point current (Impp) & $3.5 \mathrm{~A}$ \\
Open-circuit voltage (Voc) & $21.1 \mathrm{~V}$ \\
Short-circuit current (Isc) & $3.8 \mathrm{~A}$ \\
The number of cells, (NS) & 36 \\
Current/temp. coefficient (Ki) & $0.003 \%{ }^{\circ} \mathrm{C}$ \\
Voltage/temp. coefficient (Kv) & $-0.08 \mathrm{v} /{ }^{\circ} \mathrm{C}$ \\
\hline
\end{tabular}

necessary to exploit an MPPT algorithm, for the efficient working of the PV system.

2.2. DC-DC Converter. A DC-DC converter is used to control the transfer of energy from a DC source to the load with high efficiency. Depending on its structure, it can be a voltage booster or reducer converter and, under certain conditions, can return energy to the power supply.

The ideal boost converter topology is made up of an inductor $\left(L_{P V}\right)$, a capacitor $(C)$, an electronic switch, a power supply, and a diode (Figure 4). Its average state model is written as follows $[28,29]$ :

$$
\left\{\begin{array}{l}
\dot{x}_{1}=-\gamma_{2}(1-\alpha) x_{2}+\gamma_{2} V_{P V} \\
\dot{x}_{2}=-b x_{2}+\gamma_{1}(1-\beta) x_{1}
\end{array} .\right.
$$

With:

$x_{1}=I_{L}, x_{2}=V_{s}, \gamma_{1}=1 / C, \gamma_{2}=1 / L_{P V}$ et $b=1 / R C, \beta$ is the duty cycle.

The voltage conversion rate can be defined as follows:

$$
M(D)=\frac{V_{S}}{V_{P V}}=\frac{1}{1-\beta} .
$$

Where $V_{P V}$ and $V_{S}$ are, respectively, the input and output voltages of the boost converter.

\section{MPPT Control}

The MPPT control is an essential control for optimal operation of a photovoltaic system. The principle of this control is based on the automatic variation of the duty cycle by steering it to the optimum value in order to maximize the power delivered by the photovoltaic panel. There are a number of MPPT control algorithms that have been proposed in the literature, among which the two primary algorithms are incremental conductance (IC) algorithm and perturb and observe $(\mathrm{P} \& \mathrm{O})$ algorithm [30]. These algorithms use array output voltage data, output current data, or both to track the maximum power point based on a mathematical relationship derived from empirical data.

3.1. Extremum Seeking Control. This command is based on the search for the extreme of a physical variable of a system by the variation or perturbation of an input parameter of this

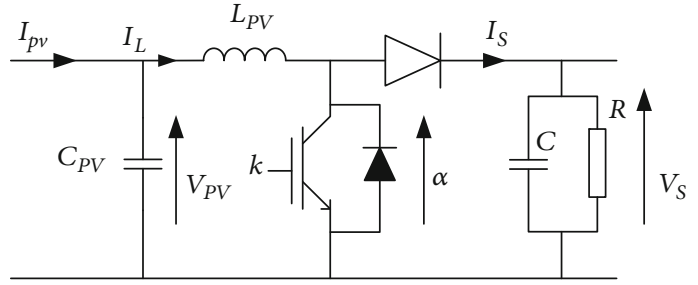

Figure 4: Circuit diagram of a DC-DC boost converter.

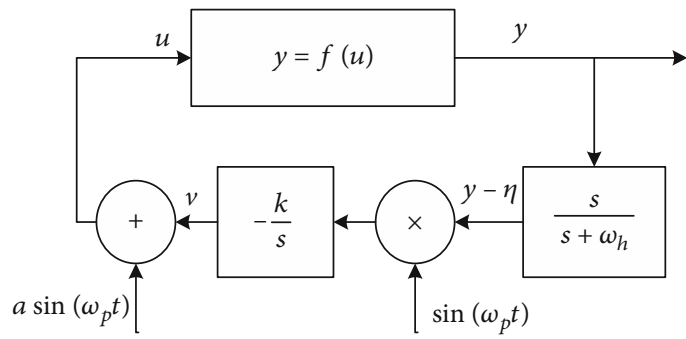

Figure 5: "Extremum seeking" loop for the system $y=f(u)$ where $f$ is unknown.

system. The extremum seeking control was reported in 1922 by Leblanc for the search of the resonance peak of an electromechanical system [31]. This optimization method has been successfully applied to a wide range of engineering applications, including peak power point tracking in renewable energy systems [32, 33], control of braking systems [34, 35], combustion engine timing control [36, 37], and mobile trajectory planning robots $[38,39]$. In the particular case of a photovoltaic generator, this control forces the operating point to approach the point of maximum power and to oscillate around it indefinitely.

In recent years, various types of ESC structures have been studied in the literature. Among the different algorithms, the sinusoidal perturbed ESC structure has attracted the most interest among researchers [40-42]. The general form of ESC structure is shown in Figure 5.

3.2. Working Principle of ESC. The idea is to iteratively adjust the input of the system in order to orient the output to its optimum value.

The algorithm uses the injection of a small dither signal $\left(\sin \left(\omega_{p} t\right)\right)$ with a relatively high frequency for optimal input (u) estimation.

This dither signal then causes the output variable $y$ to oscillate. The output signal is passed through a high-pass filter $\left(s / s+\omega_{h}\right)$. Only the oscillations caused by the excitation of the system can pass through the filter. The signal at the output of the filter is then multiplied (modulated) by the same function $\left(\sin \left(\omega_{p} t\right)\right)$ that was used to excite the system; the result becomes a gradient approximation.

The last step is to use this signal, which represents the gradient, to direct the system to the optimal point. For this purpose, this signal is multiplied by a gain (gradient update gain) and added (demodulation) to the disturbance signal, so that the signal moves in the direction where the gradient 


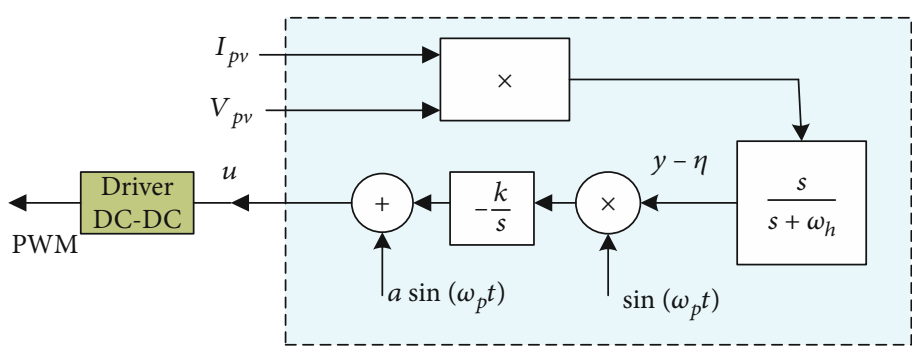

FIGURE 6: Block diagram of the conventional ESC algorithm applied to the PV system.

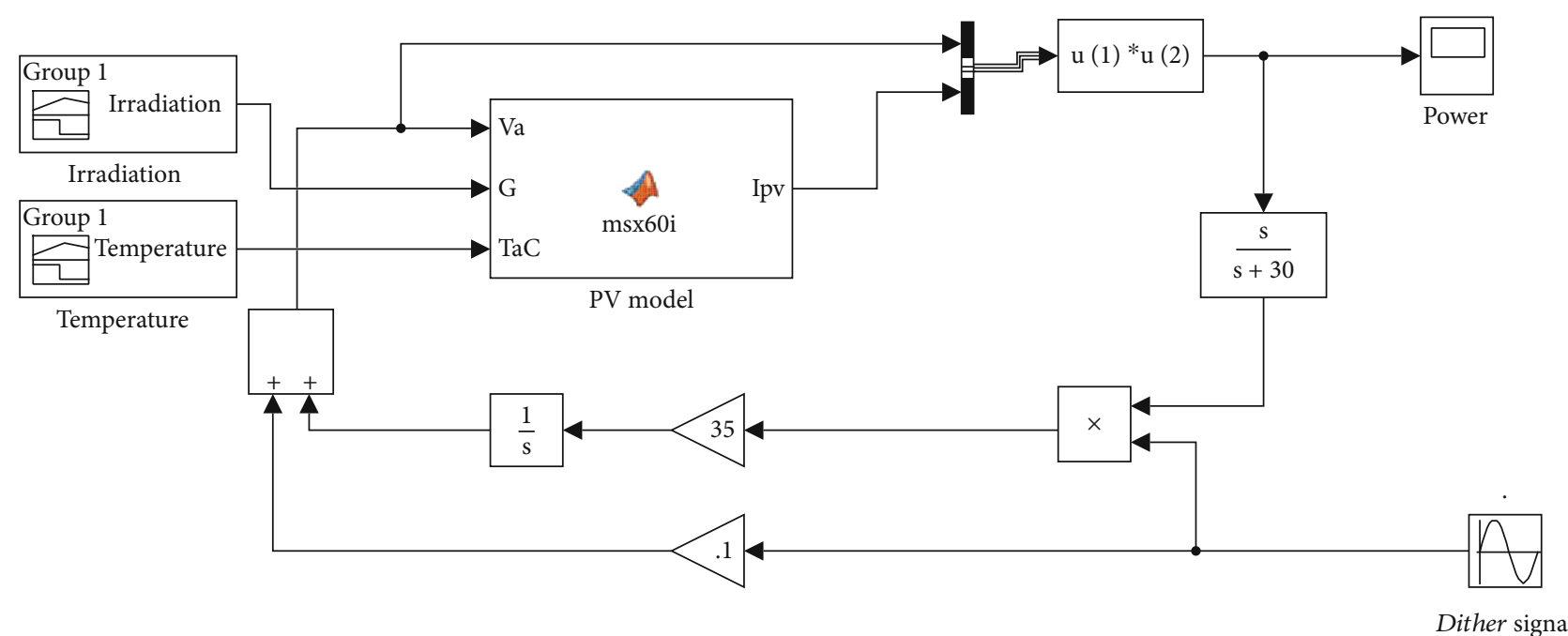

FIgURE 7: Simulink model of the conventional ESC algorithm.

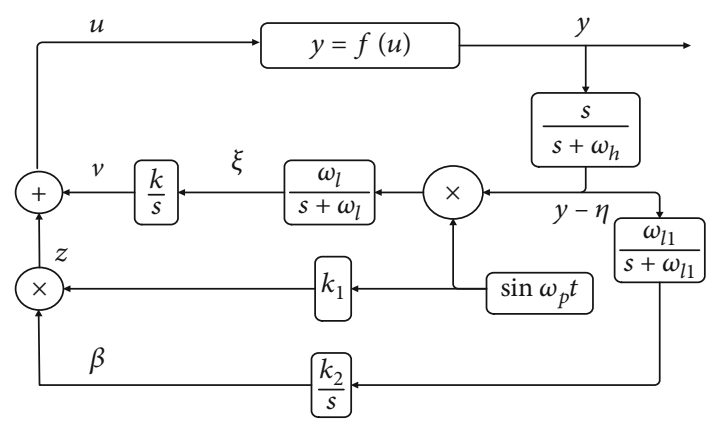

Figure 8: Modified ESC algorithm.

is the smallest, until a practically constant output is obtained (with very small variations).

The system of equations associated with the block diagram in Figure 5 is:

$$
\left\{\begin{array}{l}
\frac{d v}{d t}=-k \sin \left(\omega_{p} t\right)\left(f\left(v+a \sin \left(\omega_{p} t\right)\right)-\eta\right) \\
\frac{d \eta}{d t}=\omega_{h}\left(f\left(v+a \sin \left(\omega_{p} t\right)\right)-\eta\right) \\
y=f\left(v+a \sin \left(\omega_{p} t\right)\right)
\end{array} .\right.
$$

Where $a$ is the amplitude and $\omega_{p}$ is the frequency of the dither signal, respectively. $(y-\eta)$ is the output of the high- pass filter, $\omega_{h}$ is the cutoff frequency of the high-pass filter, and $k$ is the gradient updating gain.

It is assumed that the function $f$ admits a local minimum in $u=\bar{u}$ with the approximation $f(u) \approx \bar{f}+\left(\bar{f}^{\prime \prime} / 2\right)(u-\bar{u})^{2}$ where $\bar{f}=f(\bar{u})$ and $\bar{f}^{\prime \prime}=f^{\prime \prime}(\bar{u})>0$. For $v$ falling around $\bar{u}_{\rightarrow}$, we have the following approached system ( $a$ is very small gain).

$$
\left\{\begin{array}{l}
\frac{d v}{d t}=-k \sin \left(\omega_{p} t\right)\left(\bar{f}+\frac{\bar{f}^{\prime \prime}}{2}\left(v+a \sin \left(\omega_{p} t\right)-\bar{u}\right)^{2}-\eta\right) \\
\frac{d \eta}{d t}=\omega_{h}\left(\bar{f}+\frac{\bar{f}^{\prime \prime}}{2}\left(v+a \sin \left(\omega_{p} t\right)-\bar{u}\right)^{2}-\eta\right)
\end{array} .\right.
$$

Therefore, if the gains $\left(k, a, \omega_{h}, \omega_{p}\right)$ are such that $a k \bar{f}^{\prime \prime}>$ $>\omega_{p}$ and $\omega_{h}>>\omega_{p}$, we can use the secular approximation which consists of averaging the rapid oscillations that appear in the master equation and taking the average over a period of time. The average system is then written as [43]:

$$
\left\{\begin{array}{l}
\frac{d v}{d t}=\frac{a k \bar{f}^{\prime \prime}}{2}(\bar{u}-v) \\
\frac{d \eta}{d t}=\omega_{h}\left(\bar{f}+\frac{\bar{f}^{\prime \prime}}{2}\left((\bar{u}-v)^{2}+\frac{a}{2}\right)-\eta\right)
\end{array} .\right.
$$




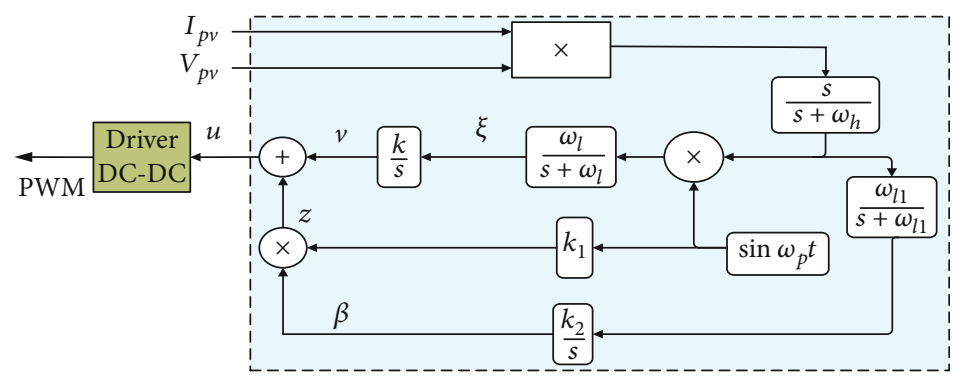

FIGURE 9: Block diagram of the modified ESC algorithm applied to the PV system.

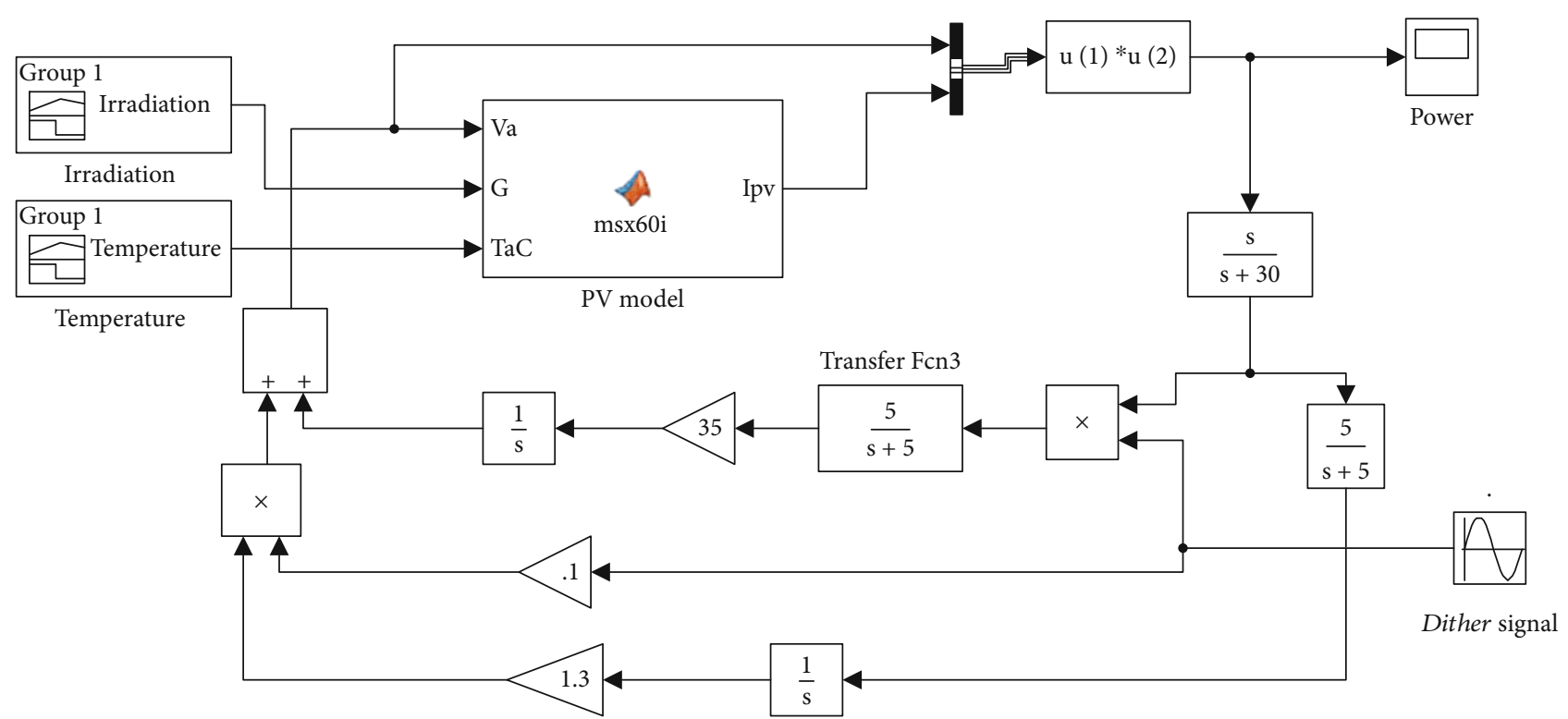

FIgURE 10: Simulink model of the modified ESC applied to the PV system.

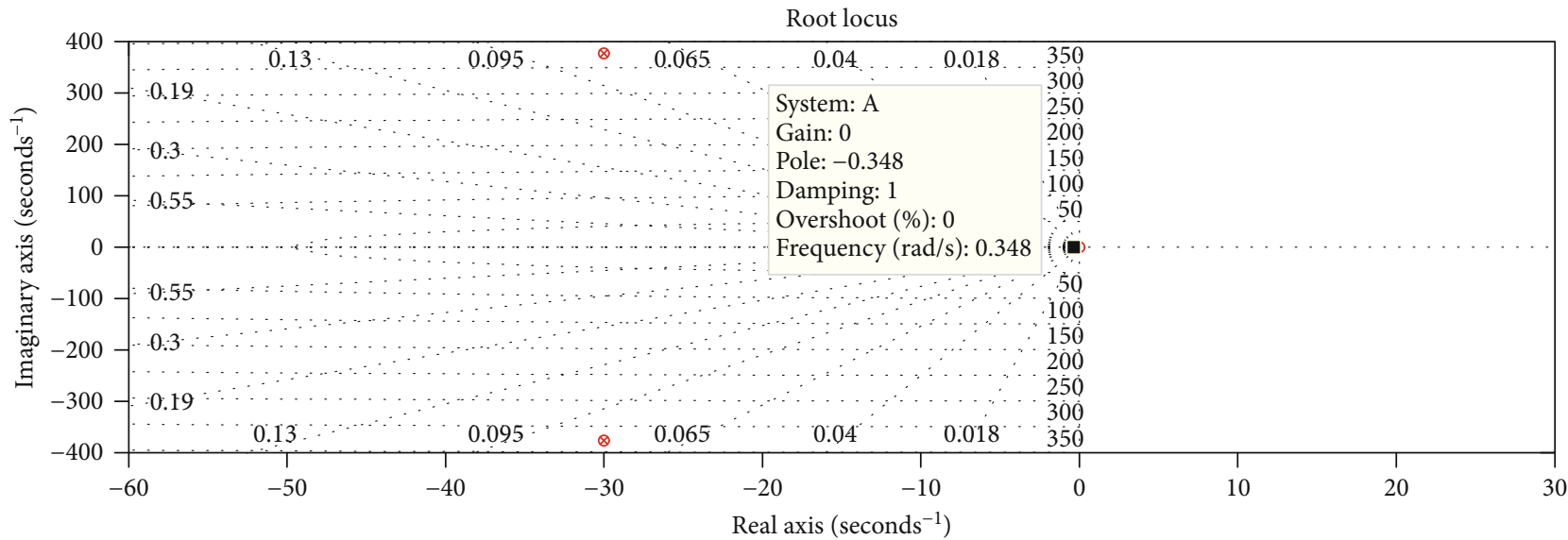

FIGURE 11: Root locus for the classical ESC algorithm.

The triangular system converges to the equilibrium point $v=\bar{u}$ and $\eta=\left(a \bar{f}^{\prime \prime} / 4\right)+\bar{f}$. Since $u=v+a \sin \left(\omega_{p} t\right)$, we can conclude that $u$ converges on average to $\bar{u}$.

Figure 6 shows a block diagram of the conventional ESC algorithm applied to the PV system.
( $I_{p v}$ and $V_{p v}$ are the current and the voltage of PV panel, respectively) and its Simulink model is presented in Figure 7.

3.3. Proposed Modified "Extremum Seeking Control" Algorithm. Although the conventional ESC method is 


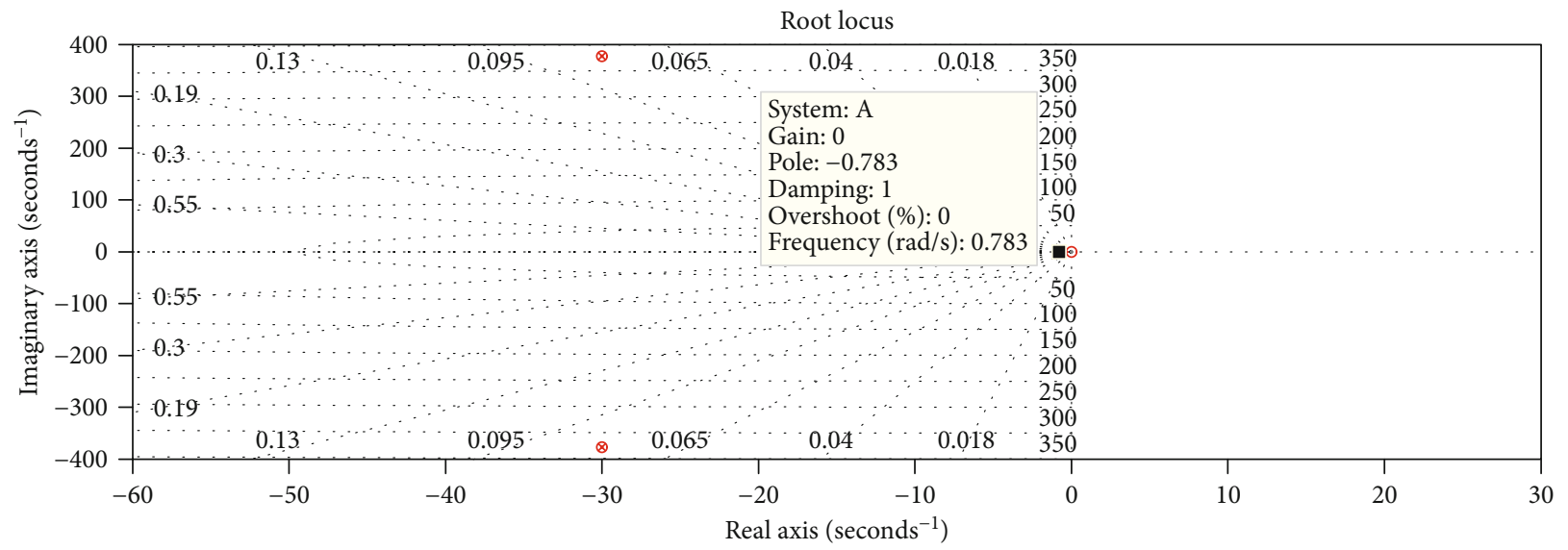

FIGURE 12: Root locus for the modified ESC algorithm.

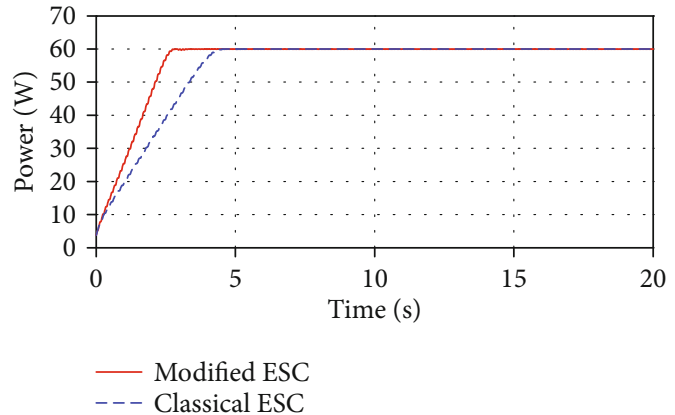

Figure 13: Power curve obtained with the modified ESC algorithm under STC $\left(25^{\circ} \mathrm{C}\right.$ and $\left.1000 \mathrm{~W} / \mathrm{m}^{2}\right)$.

advantageous over global analysis methods in terms of convergence speed [19], it still requires considerable time to converge to each maximum power point. The conventional ESC has a relatively slow transient performance [44]. We propose a modified ESC algorithm that seeks to reduce the convergence time for all maximum power points in order to increase the energy yield in photovoltaic systems during abrupt changes in atmospheric conditions. The proposed modified ESC algorithm (Figure 8) uses a slow periodic perturbation $\left(\sin \left(\omega_{p} t\right)\right)$ added to the estimated value in order to continuously drive the system to the optimal point. The operation of this algorithm is similar to the conventional method with the only difference that a second low-pass filter and an integrator are added to the system in order to increase system performance.

Its mathematical model is written as follows:

$$
\left\{\begin{array}{l}
\frac{d v}{d t}=k \xi \\
\frac{d \xi}{d t}=-\omega_{l} \xi+\omega_{l}(y-\eta) \sin \left(\omega_{p} t\right) \\
\frac{d \eta}{d t}=-\omega_{h} \eta+\omega_{h} y \\
y=f(u)=f\left(v+\beta k_{1} \sin \left(\omega_{p} t\right)\right)
\end{array}\right.
$$

TABLE 2: 5\% settling time comparison.

\begin{tabular}{lcc}
\hline MPPT method & Classical ESC & Modified ESC \\
\hline Settling time $(\mathrm{s})$ & $3,9 \mathrm{~s}$ & $2,43 \mathrm{~s}$ \\
\hline
\end{tabular}

For the sake of simplification, we pose $a_{1}=\beta k_{1}$; therefore, the system becomes:

$$
\left\{\begin{array}{l}
\frac{d v}{d t}=k \xi \\
\frac{d \xi}{d t}=-\omega_{l} \xi+\omega_{l}(y-\eta) \sin \left(\omega_{p} t\right) \\
\frac{d \eta}{d t}=-\omega_{h} \eta+\omega_{h} y \\
y=f(u)=f\left(v+a_{1} \sin \left(\omega_{p} t\right)\right)
\end{array} .\right.
$$

Where $a_{1}$ is the amplitude of the dither signal. The parameters $\omega_{p}$ (the frequency of the dither signal), $\omega_{h}$ (cutoff frequency of the high-pass filter), $\omega_{l}$ (cutoff frequency of the first low-pass filter), and $k$ (gradient update gain) have been chosen under the same conditions as in [41]. $w_{l 1}$ (cutoff frequency of the second low-pass filter) and $k_{1}$ (control gain) are obtained empirically. Figure 9 shows the block diagram of the modified ESC algorithm applied to the PV system. The resulting Simulink model is given in Figure 10.

3.4. Stability Analysis. The linearized average model is defined by [21]:

$$
\frac{\tilde{u}(s)}{u^{*}(s)}=\frac{1}{1+L(s)}
$$

Where $\tilde{u}=u-u^{*}$ is the signal error and

$$
L(s)=\frac{k a^{2}}{2 s}\left(e^{j \phi} \frac{s+j \omega_{p}}{s+j \omega_{p}+\omega_{h}}+e^{-j \phi} \frac{s-j \omega_{p}}{s-j \omega_{p}+\omega_{h}}\right) .
$$

This model can be used in the stability analysis of integer order ESC averaged model. If the phase delay of the 


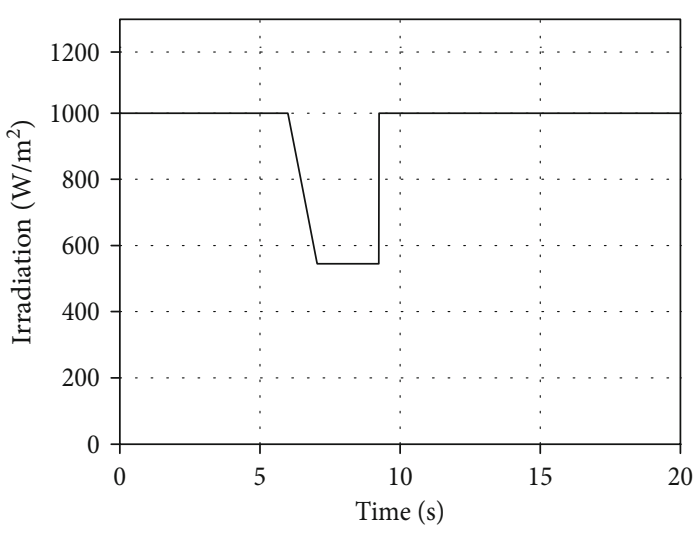

(a)

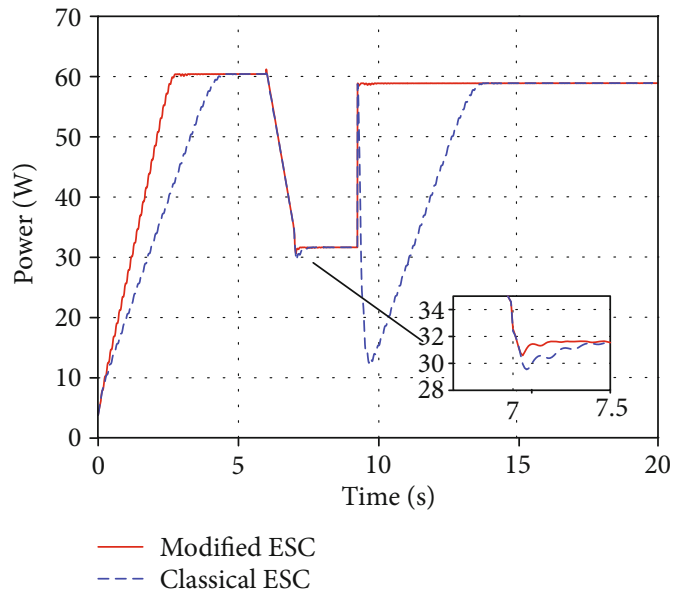

(c)

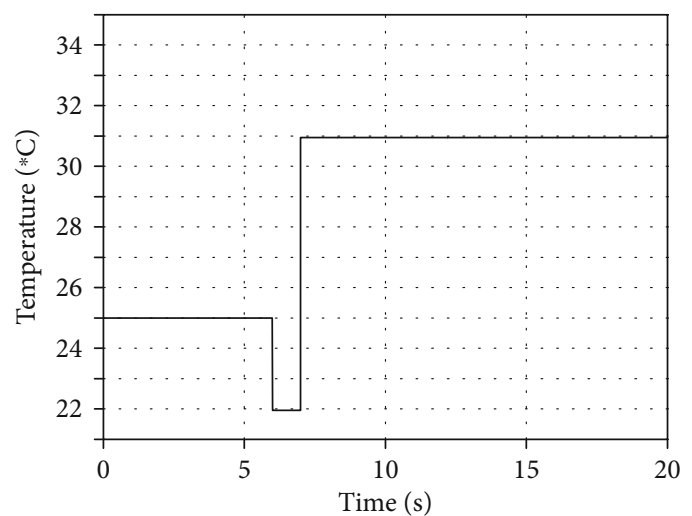

(b)

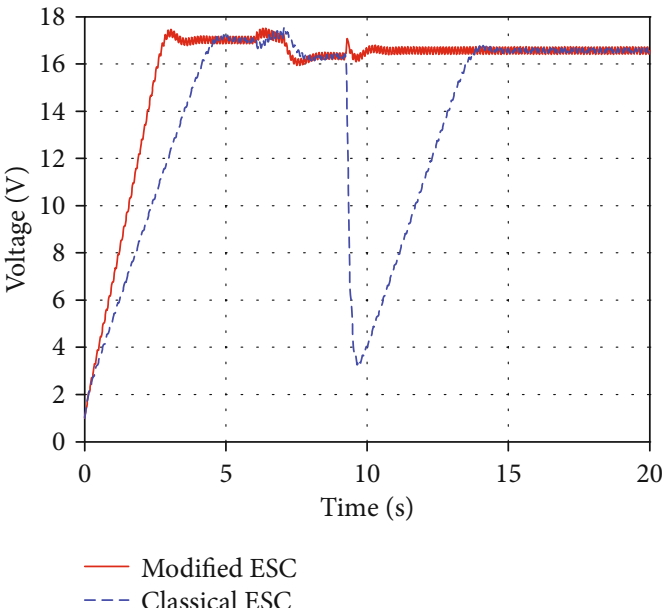

(d)

FIgURE 14: Comparative performances between modified extremum seeking control and classical extremum seeking control in the time domain.

perturbation signal, $\phi$ is presumed to be zero, then (15) is asymptotically stable for all $k>0$. For the SISO ESC of Figure 5, by assuming $\phi=0$, the averaged linearized model of (15) is:

$$
\frac{\tilde{u}(s)}{u^{*}(s)}=\frac{s\left(s^{2}+2 \omega_{h} s+\omega_{h}^{2}+\omega_{p}^{2}\right)}{s^{3}+\left(2 \omega_{h}+k a^{2}\right) s+\left(\omega_{h}^{2}+\omega_{p}^{2}+k a^{2} \omega_{h}\right) s+k a^{2} \omega_{p}^{2}} .
$$

The root locus for the conventional ESC algorithm and the modified ESC algorithm are shown in Figures 11 and 12, respectively. For the conventional ESC algorithm, the linearized average model is written as:

$$
\frac{\tilde{u}(s)}{u^{*}(s)}=\frac{s\left(s^{2}+2 \omega_{h} s+\omega_{h}^{2}+\omega_{p}^{2}\right)}{s^{3}+\left(2 \omega_{h}+k a^{2}\right) s+\left(\omega_{h}^{2}+\omega_{p}^{2}+k a^{2} \omega_{h}\right) s+k a^{2} \omega_{p}^{2}} .
$$

To plot the root locus of (18), we used the following parameters: $\omega_{h}=30 \mathrm{rad} / \mathrm{s}, k=35, a=0.1, \omega_{p}=2 \times \mathrm{pi} \times 60$ $\mathrm{rad} / \mathrm{s}$. The linearized average model of the modified ESC is written in (19)

$$
\frac{\tilde{u}(s)}{u^{*}(s)}=\frac{s\left(s^{2}+2 \omega_{h} s+\omega_{h}^{2}+\omega_{p}^{2}\right)}{s^{3}+\left(2 \omega_{h}+k a_{1}{ }^{2}\right) s+\left(\omega_{h}^{2}+\omega_{p}^{2}+k a_{1}{ }^{2} \omega_{h}\right) s+k a_{1}{ }^{2} \omega_{p}^{2}} .
$$

The root locus of (19) has been obtained using the following parameters: $\omega_{h}=30 \mathrm{rad} / \mathrm{s}, k=35, \omega_{p}=2 \times \mathrm{pi} \times 60 \mathrm{rad} / \mathrm{s}$, and $a_{1}=0.15$ are empirically obtained.

The conventional averaged ESC model has a pair of poles closer to the imaginary axis $\left(s_{\min }=-0.348\right)$. As a result, the system may become unstable for certain external perturbations (sudden changes in atmospheric conditions). For the case of the modified ESC algorithm, the pole closer to the imaginary axis is $s_{\min }=-0.783$. Given that the response time is defined by equation (20):

$$
t_{r(5 \%)}=\frac{-3}{\operatorname{Re}\left(s_{\min }\right)} .
$$



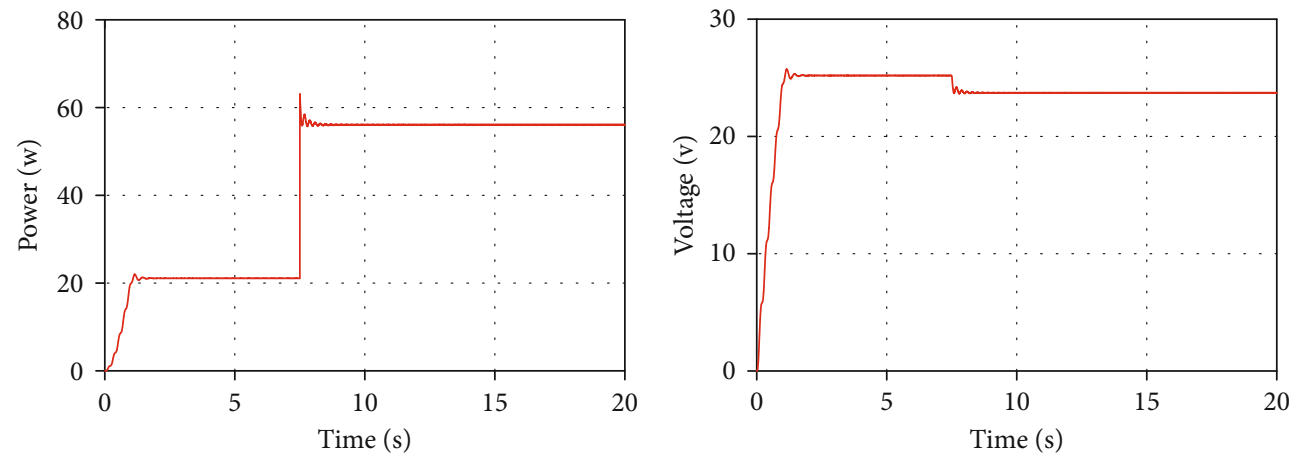

FIGURE 15: Load power and load voltage under load variation.

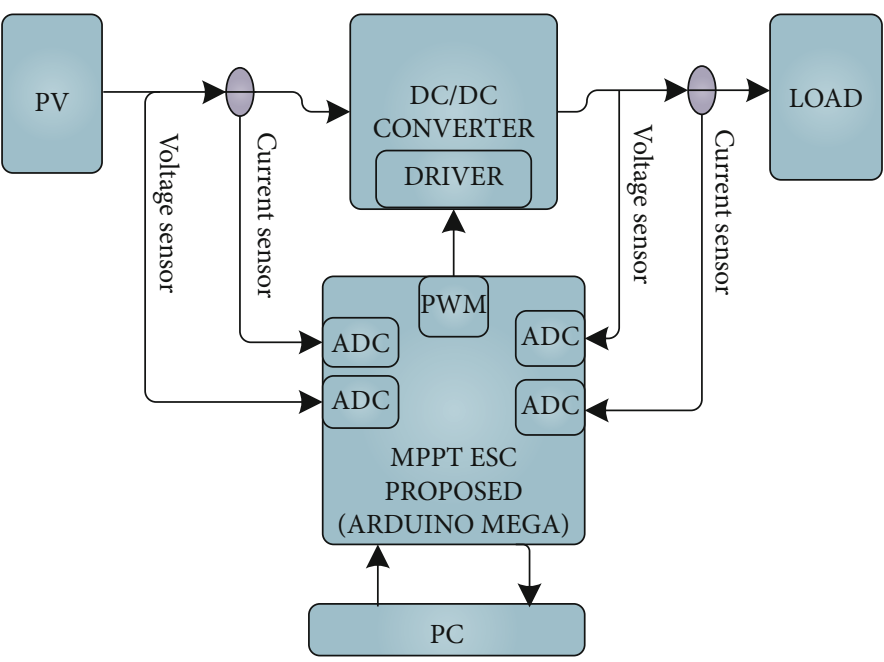

FIGURE 16: Experimental architecture.

Where $s_{\min }$ is the nonzero pole closest to the imaginary axis, we can conclude that the proposed modified ESC algorithm has a smaller response time than the classical ESC method.

\section{Simulation Results}

To demonstrate the efficiency and robustness of the proposed ESC algorithm, different simulations are performed in Matlab/Simulink environment. The MSX-60 (60 W) reference solar module from Solarex was used to generate the electrical energy in the system. The main characteristics at $25^{\circ} \mathrm{C}$ and $1000 \mathrm{~W} / \mathrm{m}^{2}$ of this module are presented in Table 1.

The parameters of the modified ESC controller and the classical ESC method are the following: $\omega_{h}=30 \mathrm{rad} / \mathrm{s}, k_{1}=$ $0.1, k_{2}=1.3, k=35 \omega_{p}=60 \mathrm{rad} / \mathrm{s}$, and $\omega_{l}=\omega_{l 1}=5 \mathrm{rad} / \mathrm{s}$.

Initially, the modified ESC algorithm is implemented, and its performance is evaluated during standard atmospheric conditions $\left(25^{\circ} \mathrm{C}\right.$ and $\left.1000 \mathrm{~W} / \mathrm{m}^{2}\right)$. Then, another simulation is performed during sudden changes in temperature and irradiation. Finally, the proposed MPPT algorithm is tested in variable load condition. The results are compared with those of classical ESC algorithm.
TABLE 3: DC/DC converter characteristics.

\begin{tabular}{lc}
\hline Converter parameters & Value \\
\hline Stray capacitance $C_{p v}$ & $120 \mu \mathrm{F}$ \\
Boost inductor $L_{p v}$ & $82 \mathrm{mH}$ \\
Boost switching frequency & $490 \mathrm{~Hz}$ \\
Boost output capacitor $C$ & $47 \mu \mathrm{F}$ \\
Load resistance $R$ & $580 \Omega, 30 \Omega, 10 \Omega$
\end{tabular}

Figure 13 shows that during standard atmospheric conditions $\left(25^{\circ} \mathrm{C}\right.$ and $\left.1000 \mathrm{~W} / \mathrm{m}^{2}\right)$, the proposed controller indeed reaches the maximum power point $(60 \mathrm{~W}$ as indicated in the MSX60 datasheet) in shorter time than the classical method. This fact is clearly emphasized by comparing the $5 \%$ settling time as shown in Table 2.

In the second simulation, a comparative study between the modified ESC algorithm and the classical ESC algorithm is established. For a fair comparison between the two algorithms, all parameters, such as the perturbation frequency, $\omega_{p}=60 \mathrm{rad} / \mathrm{s}$, the high-pass filter cut-off frequency $\omega_{\mathrm{h}}=30$ $\mathrm{rad} / \mathrm{s}$, and the integrator gain $k=35$, are considered identical under these conditions; the behavior of the modified ESC 


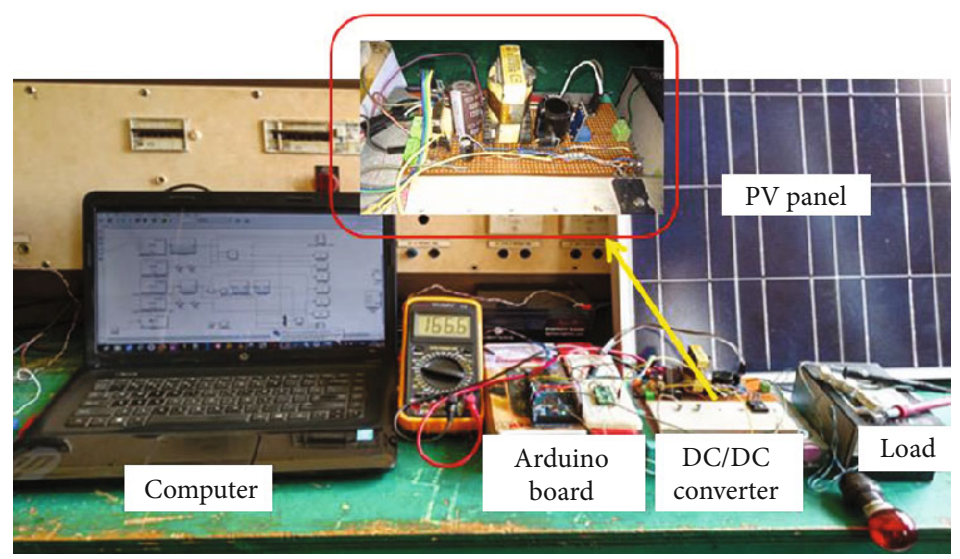

FIGURE 17: Test bench for experimental validation of the proposed algorithm.
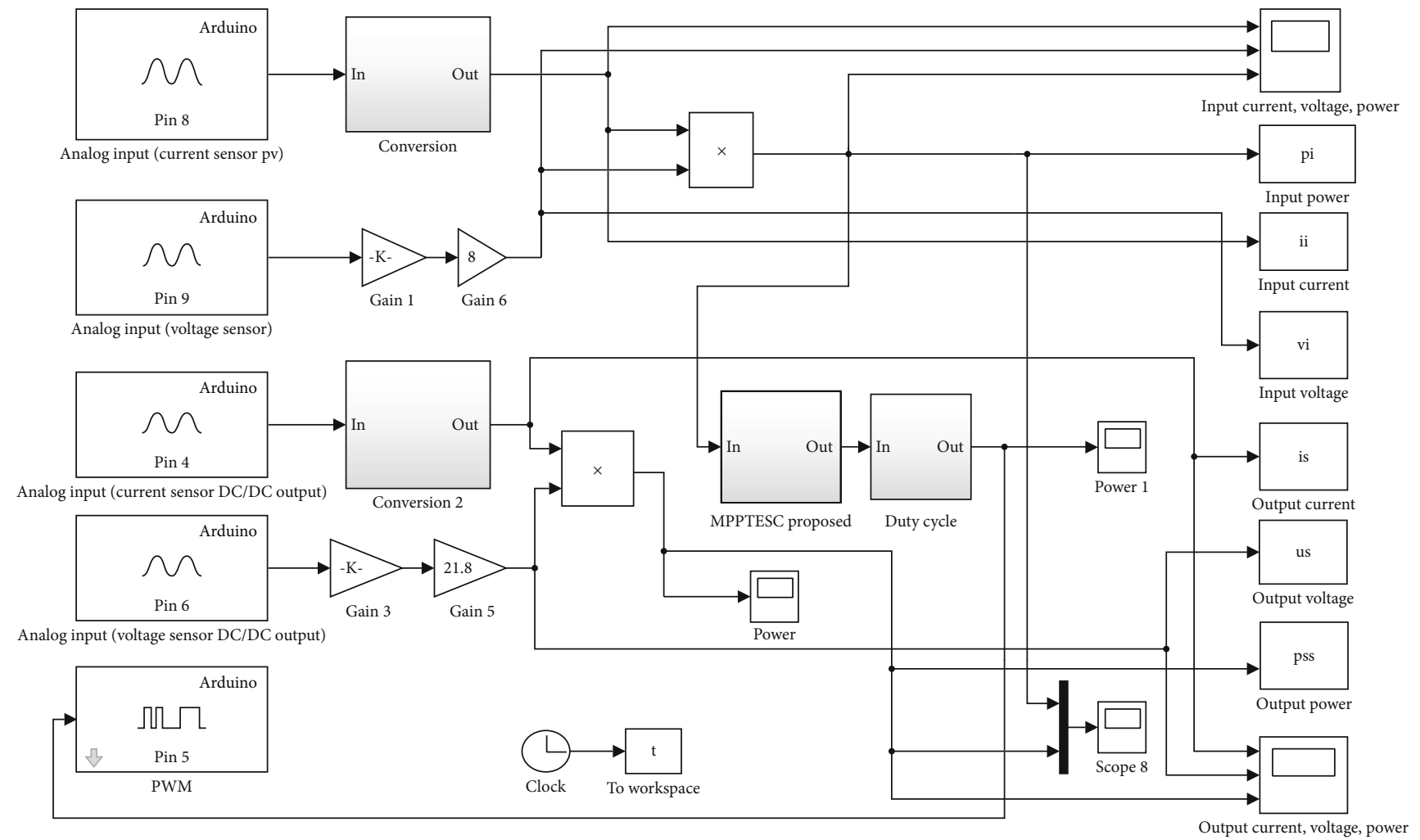

FIgURE 18: Experimental design of the proposed algorithm using Arduino under Matlab Simulink.

method and the conventional ESC method is shown in Figure 14. At time $t=6 \mathrm{~s}$, the solar irradiation is abruptly changed from $G=1000 \mathrm{~W} / \mathrm{m}^{2}$ to $G=545 \mathrm{~W} / \mathrm{m}^{2}$ and at time $t=9.25 \mathrm{~s}$ a step change from $G=545 \mathrm{~W} / \mathrm{m}^{2}$ to $G=1000 \mathrm{~W} /$ $\mathrm{m}^{2}$ is carried. Two-step changes are performed on the temperature (from $T=25^{\circ} \mathrm{C}$ to $T=25^{\circ} \mathrm{C}$ at time $t=7 \mathrm{~s}$ and from $T=25^{\circ} \mathrm{C}$ to $T=31^{\circ} \mathrm{C}$ ). It is seen on Figure 14 that the conventional method takes longer time to reach the maximum power point, while the proposed modified ESC controller rapidly converges to the maximum power point. The MPP observed on this figure are predictable from the MSX60 characteristics presented on Figure 3. In addition, it is observed that the proposed ESC controller responds quickly to radical changes in irradiance and therefore reducing the energy losses. The instantaneous change in irradiance imposed on the PV system in this simulation may be much faster than a real scenario, but it gives an idea of the time taking by the proposed controller to respond to a change in irradiance.

The proposed MPPT algorithm is tested under load variation, and the result is presented in Figure 15. For this test, the load resistance is varied from $30 \Omega$ to $10 \Omega$ at time $t=$ $7.5 \mathrm{~s}$ (STC). It is observed in Figure 15 that the load power increases rapidly from $20.1 \mathrm{~W}$ to $56.33 \mathrm{~W}$. Thus, the proposed algorithm is also able to work under load variation. 

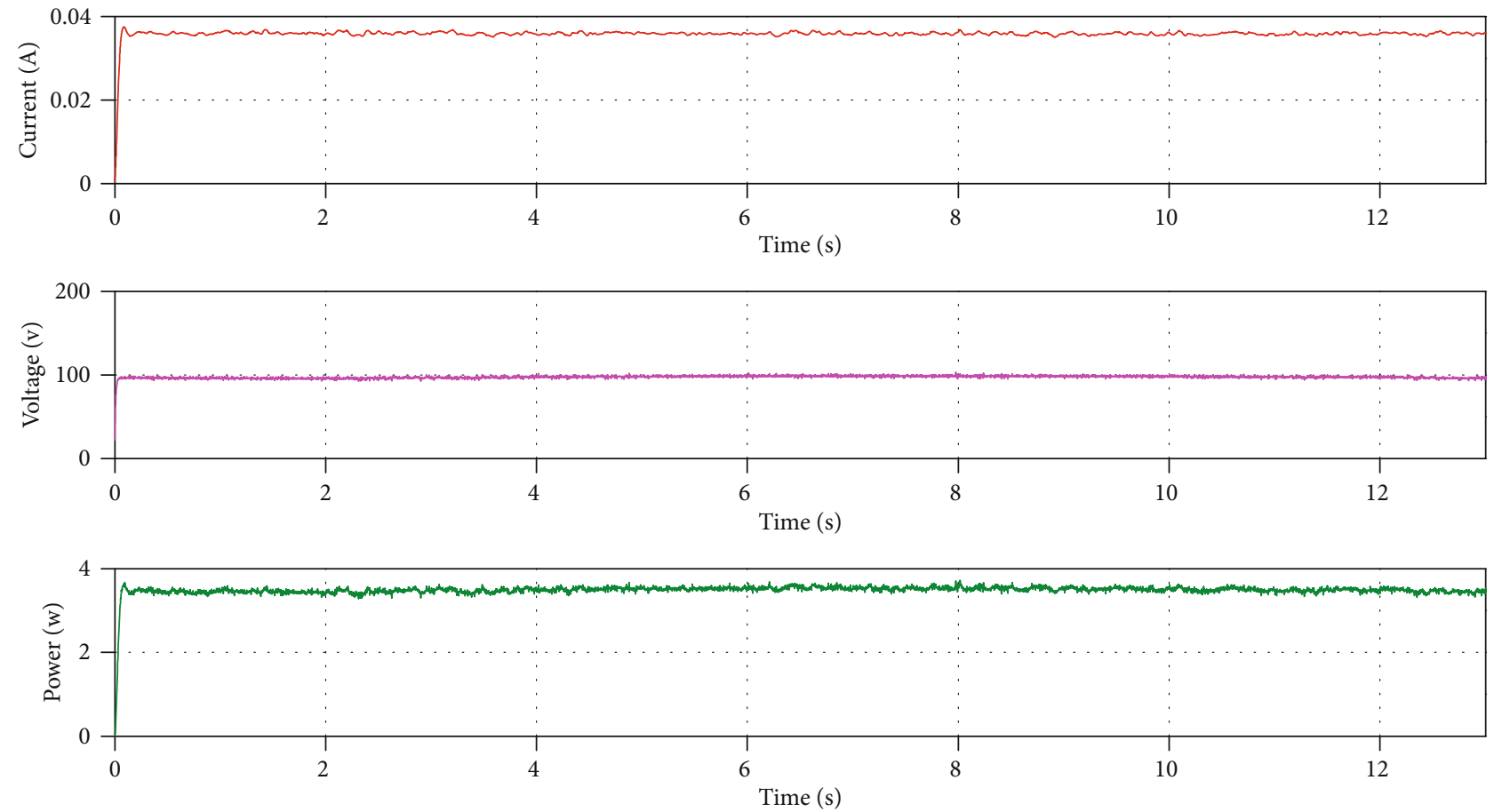

FIGURE 19: Experimental results of the proposed MPPT controller during uniform irradiance.
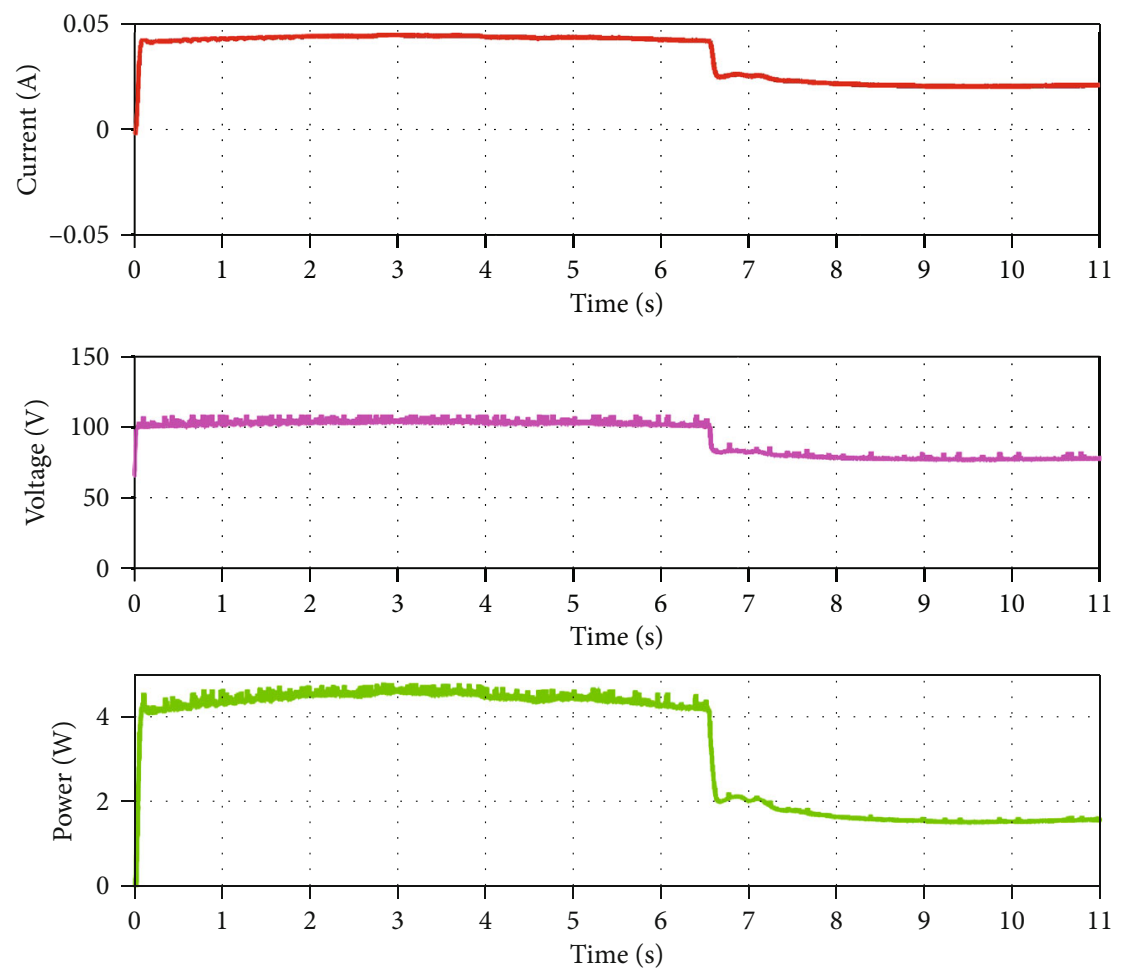

FIgURE 20: Experimental results of the proposed MPPT controller during a sudden energy change.

\section{Experimental Results}

An experimental design as shown in Figure 16 is assembled in the laboratory in order to validate in real time the proposed MPPT method. The experimental architecture of the system was built using an MSX-60 solar panel, a personal computer (to design of the proposed algorithm), a BOOST DC/DC converter, a resistive load, and a control circuit. The parameters of the DC/DC converter are given in Table 3. The control circuit uses Arduino Mega board 

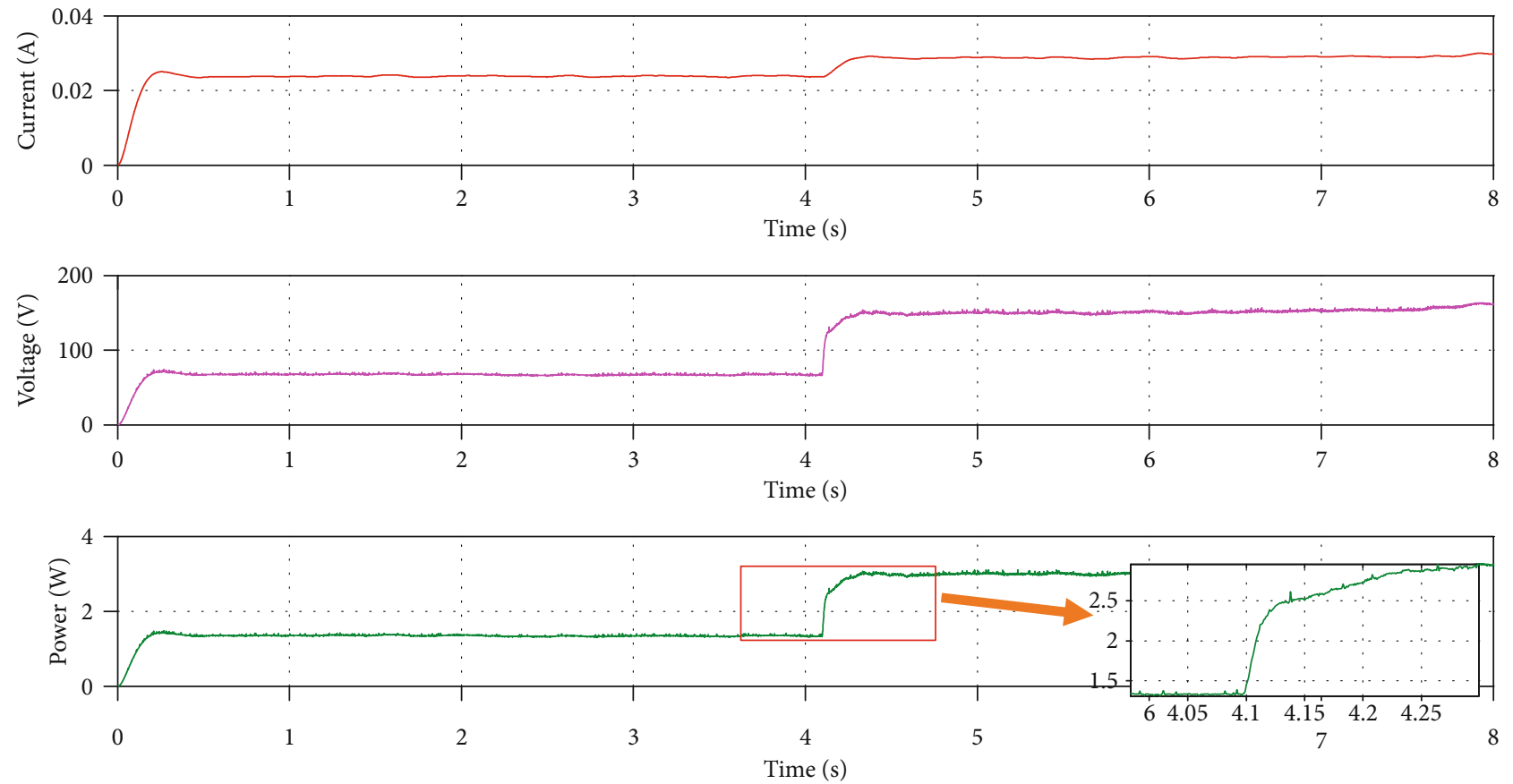

FIGURE 21: Experimental results (current, voltage, and power) of the MPPT controller based on conventional ESC.
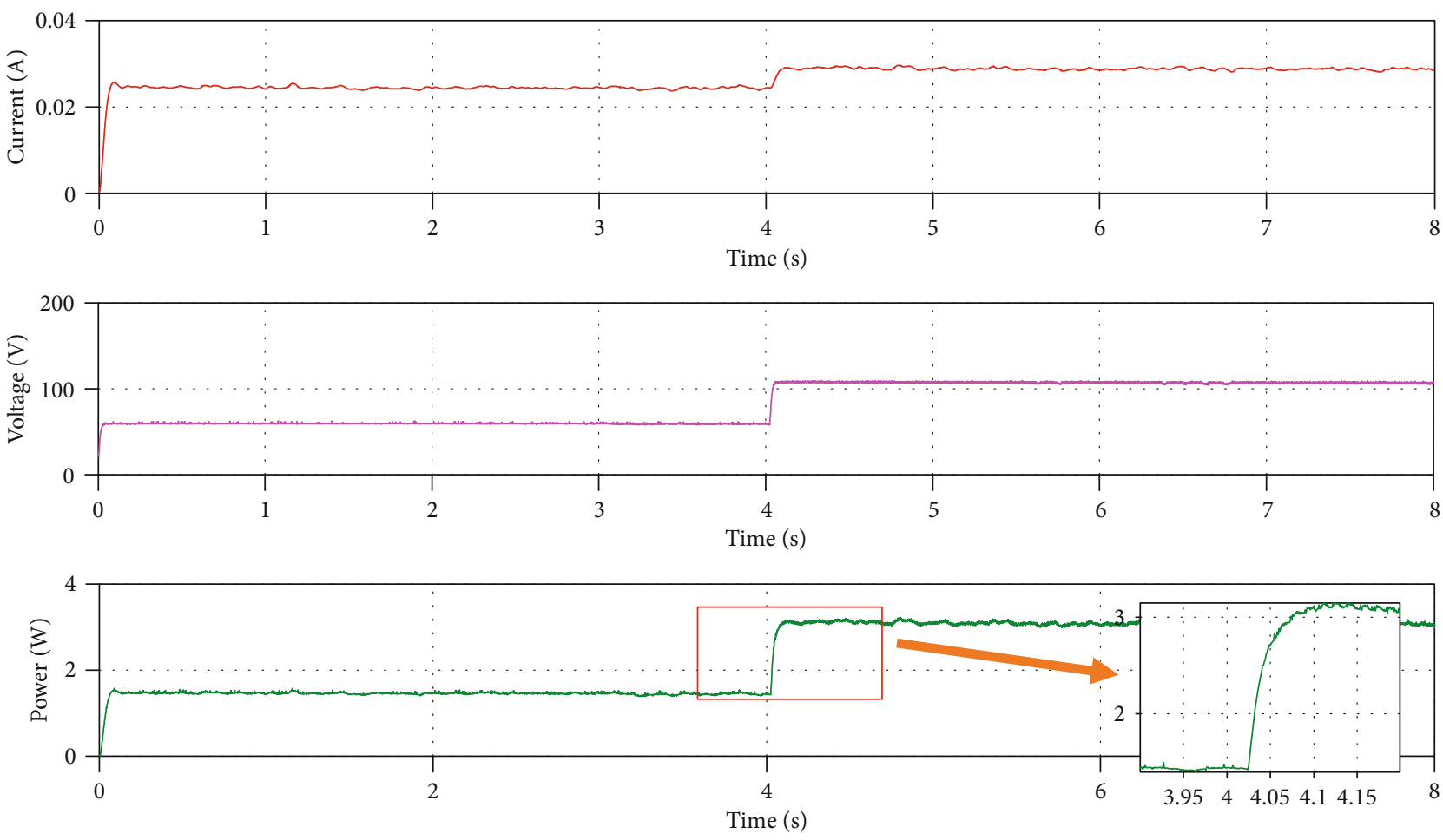

FIGURE 22: Experimental results (current, voltage, and power) of the modified MPPT controller during an irradiation change.

to execute the proposed MPPT algorithm and provide the external PWM signal needed to control the BOOST converter.

The control circuit uses Arduino Mega board to execute the proposed MPPT algorithm and provide the external PWM signal needed to control the BOOST converter. Two ACS 712 (30A) reference Hall-effect sensors are exploited; one detects the output current of the photovoltaic solar panel, and the other detects the current in the load. The output voltage of the array and the voltage across the load were detected using two voltage dividers. The proposed algorithm was realized and compiled in the Matlab/Simulink environment. The program was uploaded in real time to Arduino card to drive the whole system. 

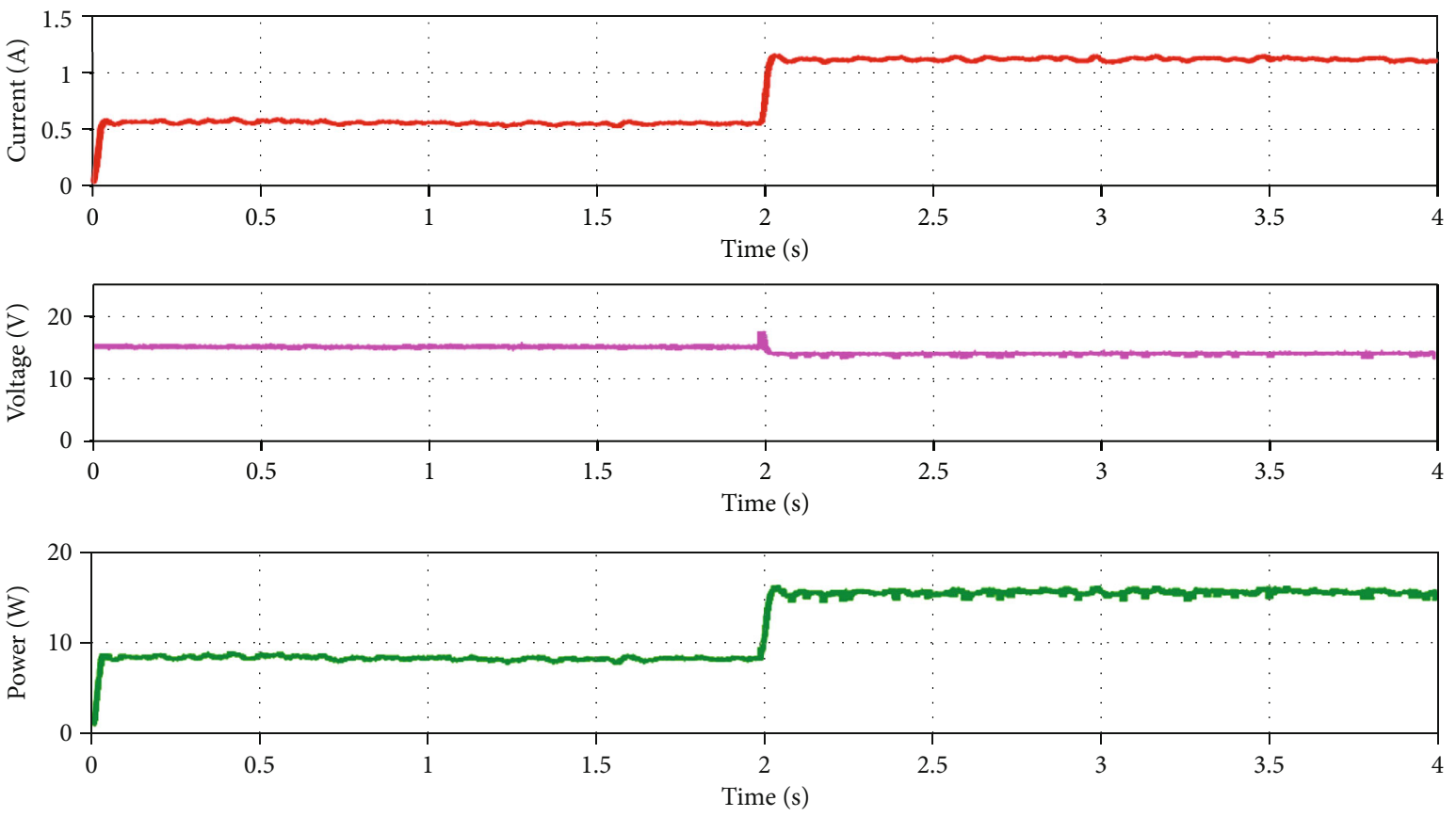

FIGURE 23: Experimental results (current, voltage, and power) of the modified MPPT controller under load variation condition.

A series of tests were conducted in the laboratory using the hardware architecture shown in Figure 17 in order to experimentally validate the efficiency of the proposed MPPT controller.

The block diagram showing the implementation of the proposed controller using Arduino Mega board under Matlab Simulink Is given in Figure 18.

Figure 19 shows the experimental results when the solar panel is subjected to almost uniform irradiance. These results confirm the ability of the proposed controller to ensure the stability and efficiency of the system during stable atmospheric conditions.

In Figure 20, the system starts with nearly constant irradiance, but at $t=6,5 \mathrm{~s}$, the irradiance is abruptly reduced. This scenario is obtained by exposing only a part of the solar panel to the sunlight after a certain period of time. During this abrupt change in irradiance, the results show that the modified ESC controller detects and follows a rapid transient response and able steady-state response.

Figures 21 and 22 show the experimental results of the conventional ESC-based MPPT controller and the modified ESC-based MPPT controller during the irradiation abrupt change, respectively. This scenario is obtained by exposing part of the solar panel to sunlight a certain starting with a partially shaded PV array; then at time $t=4,3 \mathrm{~s}$, the shadow is abruptly removed. It is observed that during this scenario, both conventional and proposed MPPT accurately track the maximum power point. However, the modified ESC-based MPPT controller reaches the maximum power point with a shorter time than the conventional ESC-based MPPT controller.

Figure 23 presents experimental results obtained with the modified ESC under load variation test. The test condition is the same as in the case of simulation (i.e., the load varied from $30 \Omega$ to $10 \Omega$ ). The PV array voltage decreases, while the current increases. The proposed algorithm responds to the load variation rapidly.

\section{Conclusion}

In this work, an intelligent control technique based on the ESC has been proposed. The proposed ESC method uses an additional feedback loop to improve the system performance. A detailed analysis of the stability of this algorithm was performed using a linearized average model. This analysis reveals how the special features of the proposed extremum search algorithm affect and enhance the overall convergence and robustness of the system. In addition, the paper compares the proposed MPPT strategy with an approach based on classical ESC. Simulation of both MPPT approaches was performed in MATLAB/Simulink environment real-time implementation using Arduino board. Based on the simulation and experimental results, it is concluded that the proposed algorithm accurately tracks the maximum power point with a shorter time during abrupt changes in atmospheric conditions.

\section{Data Availability}

All the data used to support the findings of this study are included within the paper.

\section{Conflicts of Interest}

The authors declare that they have no conflicts of interest. 


\section{References}

[1] M. Le Feuvre and M. A. Wieczorek, "Nonuniform cratering of the Moon and a revised crater chronology of the inner Solar System," Icarus, vol. 214, no. 1, pp. 1-20, 2011.

[2] C. Yin, Y. Q. Chen, B. Stark, and S. M. Zhong, "Extremum seeking control with fractional-order switching technique design for maximum power point tracking in photovoltaic systems," in 54th IEEE Conference on Decision and Control (CDC), pp. 5629-5634, 2015.

[3] D. Parra, M. Gillott, S. A. Norman, and G. S. Walker, "Optimum community energy storage system for PV energy time-shift," Applied Energy, vol. 137, pp. 576-587, 2015.

[4] S. Sajadian and R. Ahmadi, "Distributed maximum power point tracking using model predictive control for photovoltaic energy harvesting architectures based on cascaded power optimizers," IEEE Journal of Photovoltaics, vol. 7, no. 3, pp. 849857, 2017.

[5] W. Chen, Y. Duan, L. Guo, Y. Xuan, and X. Yang, "Modeling and prediction of radiated emission from solar cell in a photovoltaic generation system," IEEE Journal of Photovoltaics, vol. 6, no. 2, pp. 540-545, 2016.

[6] A. D. Mills and R. H. Wiser, "Changes in the economic value of photovoltaic generation at high penetration levels: a pilot case study of California," IEEE Journal of Photovoltaics, vol. 3, no. 4, pp. 1394-1402, 2013.

[7] A. Bidram, A. Davoudi, and R. S. Balog, "Control and circuit techniques to mitigate partial shading effects in photovoltaic arrays," IEEE Journal of Photovoltaics, vol. 2, no. 4, pp. 532546, 2012.

[8] B. Bose, P. Szczesny, and R. Steigerwald, "Microcomputer control of a residential photovoltaic power conditioning system," IEEE Transactions on Industry Applications, vol. IA-21, no. 5, pp. 1182-1191, 1985.

[9] R. A. Mastromauro, M. Liserre, T. Kerekes, and A. Dell'Aquila, "A single phase voltage-controlled grid-connected photovoltaic system with power quality conditioner functionality," IEEE Transactions on Industrial Electronics, vol. 56, no. 11, pp. 4436-4444, 2009.

[10] T. Esram and P. L. Chapman, "Comparison of photovoltaic array maximum power point tracking techniques," Energy Conversion, IEEE Transactions, vol. 22, no. 2, pp. 439-449, 2007.

[11] J. Nedumgatt, K. Jayakrishnan, S. Umashankar, D. Vijayakumar, and D. Kothari, "Perturb and observe mppt algorithm for solar pv systems modeling and simulation," in India Conference (INDICON), Annual IEEE, pp. 1-6, 2011.

[12] R. Alonso, P. Ibaez, V. Martinez, E. Roman, and A. Sanz, “An innovative perturb, observe and check algorithm for partially shaded pv systems," in Power Electronics and Applications,. EPE '09. 13th European Conference, pp. 1-8, 2009.

[13] N. Femia, G. Petrone, G. Spagnuolo, and M. Vitelli, “Optimization of perturb and observe maximum power point tracking method," IEEE Transactions on Power Electronics, vol. 20, no. 4, pp. 963-973, 2005.

[14] G. J. Kish, J. J. Lee, and P. Lehn, "Modelling and control of photovoltaic panels utilising the incremental conductance method for maximum power point tracking," IET Renewable Power Generation, vol. 6, no. 4, pp. 259-266, 2012.

[15] A. Safari and S. Mekhilef, "Simulation and hardware implementation of incremental conductance mppt with direct con- trol method using cuk converter," IEEE Transactions on Industrial Electronics, vol. 58, no. 4, pp. 1154-1161, 2011.

[16] J. Li and H. Wang, "A novel stand-alone PV generation system based on variable step size INC MPPT and SVPWM control," in Proceedings of the 6th IEEE International Power Electronics and Motion Control Conference (IPEMC '09), pp. 2155-2160, 2009.

[17] N. Femia, G. Petrone, G. Spagnuolo, and M. Vitelli, "Optimizing duty-cycle perturbation of P\&O MPPT technique," in Proceedings of the 35th IEEE Annual Power Electronics Specialists Conference (PESC '04), pp. 1939-1944, 2004.

[18] R. Faranda and S. Leva, "Energy comparison of mppt techniques for pv systems," WSEAS TRANSACTIONS on POWER SYSTEMS, vol. 3, no. 6, pp. 1-6, 2008.

[19] S. L. Brunton, C. W. Rowley, S. R. Kulkarni, and C. Clarkson, "Maximum power point tracking for photovoltaic optimization using ripple-based extremum seeking control," IEEE Transaction on Power Electronics, vol. 25, no. 10, pp. 25312540, 2010.

[20] F. Belhachat and C. Larbes, "A review of global maximum power point tracking techniques of photovoltaic system under partial shading conditions," Renewable and Sustainable Energy Reviews, vol. 92, pp. 513-553, 2018.

[21] M. Krstic, "Performance improvement and limitations in extremum seeking control," Systems \& Control Letters, vol. 39, no. 5, pp. 313-326, 2000.

[22] H. Malek and Y. Chen, "A single-stage three-phasegridconnected photovoltaic system with fractional order MPPT," Proceedings of the Applied Power ElectronicsConference and Exposition, 2014, pp. 1793-1798, IEEE, 2014.

[23] S. J. Moura and Y. A. Chang, "Lyapunov-based switched extremum seeking for photovoltaic power maximization," Control Engineering Practice, vol. 21, no. 7, pp. 971-980, 2013.

[24] G. Masters, Renewable and Efficient Electric Power Systems, Wiley Online. Library, 2004.

[25] G. Vachtsevanos and K. Kalaitzakis, "A Hybrid Photovoltaic Simulator for Utility Interactive Studies," IEEE Transactions on Energy Conversion, 1987, pp. 227-231, 1987.

[26] H. El Fadil and F. Giri, "Climatic sensorless maximum power point tracking in pv generation systems," Control Engineering Practice, vol. 19, no. 5, pp. 513-521, 2011.

[27] M. G. Villalva, J. R. Gazoli, and E. R. Filho, "Comprehensive approach to modeling and simulation of photovoltaic arrays," IEEE Transactions on Power Electronics, vol. 24, no. 5, pp. 1198-1208, 2009.

[28] N. Khemiri, A. Khedher, and M. F. Mimouni, "A sliding mode control approach applied to a photovoltaic system operated in MPPT," in Proceedings of Systems, Signals \& Devices (SSD), 2013 10th International Multi-Conference, pp. 1-6, Hammamet, Tunisia, 2013.

[29] A. Nabulsi, "A. Efficiency Optimization of a DSP-Based Standalone PV System Using Fuzzy Logic and Dual-MPPT Control Industrial Informatics," IEEE Transactions, no. 3, pp. 573-584, 2012.

[30] H. Li, J. Peng, W. Liu, Z. Huang, and K. C. Lin, “A NewtonBased Extremum Seeking MPPT Method for Photovoltaic Systems with Stochastic Perturbations," International Journal of Photoenergy, vol. 2014, Article ID 938526, 13 pages, 2014.

[31] A. Neçaibia, Contribution à la commande $\mathrm{pi}^{\lambda} \mathrm{d}^{\mu}$ adaptative et aux régulateurs auto-ajustables d'ordre fractionnaire, thèse de doctorat, université du 20 août 1955, de skikda, 2016. 
[32] X. Li, Y. Li, and J. Seem, "Maximum power point tracking for photovoltaic system using adaptive extremum seeking control," IEEE Transactions on Control Systems Technology, vol. 21, no. 6, pp. 2315-2322, 2013.

[33] A. Ghaffari, M. Krstic, and S. Seshagiri, "Power optimization for photovoltaic microconverters using multivariable Newton-based extremum seeking," IEEE Transactions on Control Systems Technology, vol. 22, no. 6, pp. 2141-2149, 2014.

[34] E. Dincmen, B. A. Guvenc, and T. Acarman, "Extremum-seeking control of ABS braking in road vehicles with lateral force improvement," IEEE Transactions on Control Systems Technology, vol. 22, no. 1, pp. 230-237, 2014.

[35] S. Drakunov, U. Ozguner, P. Dix, and B. Ashra, "ABS control using optimum search via sliding modes," IEEE Transactions on Control Systems Technology, vol. 3, no. 1, pp. 79-85, 1995.

[36] N. J. Killingsworth, S. M. Aceves, D. L. Flowers, F. EspinosaLoza, and M. Krstic, "HCCI engine combustion-timing control: optimizing gains and fuel consumption via extremum seeking," IEEE Transactions on Control Systems Technology, vol. 17, no. 6, pp. 1350-1361, 2009.

[37] E. Hellstrom, D. Lee, L. Jiang, A. Stefanopoulou, and H. Yilmaz, "On-board calibration of spark timing by extremum seeking for flex-fuel engines," IEEE Transactions on control systems technology, vol. 21, no. 6, pp. 2273-2279, 2013.

[38] Y. Zhang and N. Gans, "Extremum Seeking Control of a Nonholonomic Mobile Robot with Limited Field of View," in American Control Conference (ACC13), pp. 2765-2771, 2013.

[39] P. Binetti, K. Ariyur, M. Krstic, and F. Bernelli, "Control of formation flight via extremum seeking," in Proceedings of the American Control Conference (ACC02), vol. 4, pp. 28482853, 2002.

[40] Y. Tan, W. Moase, C. Manzie, D. Nesic, and I. M. Y. Mareels, "Extremum Seeking from 1922 to 2010," in 29th Chinese Control Conference (CCC10), pp. 14-26, 2010.

[41] H. Malek, S. Dadras, and Y. Chen, "Performance analysis of fractional order extremum seeking control," ISA Transaction, vol. 63, pp. 281-287, 2016.

[42] R. Leyva, C. Olalla, H. Zazo et al., "MPPT Based on sinusoidal extremum-seeking control in PV generation," International Journal of Photoenergy, vol. 2012, 7 pages, 2012.

[43] N. Petit and P. Rouchon, "Automatique: Dynamique et contrôle des systèmes," in Notes de cours, École d'Ingénieur, pp. 178-179, MINES Paris Tech, 2013.

[44] M. Guay and D. Dochain, "A time-varying extremum-seeking control approach,” Automatica, vol. 51, pp. 356-363, 2015. 